\title{
Analyzing the Sociability Potential of Golha Street, Kermanshah, Iran
}

\author{
Peyman Amiriparyan*, Zohreh Kiani, Christa Reicher \\ Urban Design Department, RWTH Aachen University, Aachen 52062, Germany
}

Corresponding Author Email: peyman.amiriparyan@rwth-aachen.de

https://doi.org/10.18280/ijsdp.150302

Received: 20 November 2019

Accepted: 3 February 2020

\section{Keywords:}

space syntax, integration, connectivity, depthmap, public space, sociability potential, street

\begin{abstract}
Detailed This paper is the initial part of ongoing doctoral research at the department of architecture and urban design at RWTH Aachen University, aiming to study the sociability potential of urban spaces in global scale in the Kermanshah city in Iran and Golha street in local scale as one of the densest urban areas from socio-economic and urban fabric perspective. To achieve this purpose a mixed research methodology in three steps is implemented, including library research, then integration analysis of the spatial configuration of Kermanshah city and Golha Street through space syntax method (depthmap) in both global and local analysis and a field study based on a questionnaire technique in which the gathered data are analyzed with SPSS software. The comparative analogy of the results of depthmap and questionnaire shows there is a meaningful relationship between the higher integrated urban spaces in Kermanshah city, specially Golha Street and sociability potential the urban spaces based on the indicators of the questionnaire.
\end{abstract}

\section{INTRODUCTION}

Human societies are spatial phenomena [1]. Principally, spatial phenomena result from the social activities in urban spaces, creating a two-dimensional concept of society-space, as far as Henry [2] believes there is a difference between "the Urban" and "the City" that is between the life of the city and the material form of the city [3]. Hence, by taking the assumption of the social and material city into account, studying the relationship between them is necessary to understand the socio-spatial nature of cities, as Bill [4] claims the most important question about the cities is exactly how is the physical city linked to the human city socially?

Space has an active and structured engagement with social life, and without understanding this, one cannot fully realize the theoretical promise of the social study of space. Space does not have a meaningful existence independent of social agency, that there is then no question of space having laws of its own, and certainly, space can have no agency in human affairs [5]. Theoretically, such discussions have persuaded many researchers to study the nature of cities from the socio-spatial point of view, especially Bill and Julienne [1]. From the perspective of design and planning, the socio-spatial study of the city is about adapting the physical spatial surroundings for human purposes leading to facilitating city natural flows and movements and enhancing the efficiency of social life in the urban fabric.

\section{URBAN SOCIO-SPATIAL ANALYSIS}

Studying the socio-spatial nature of cities is about understanding the spatial configuration of the city shaped as a result of the sequential sequences of social processes in urban spaces. Analysis of spatial configuration provides a powerful tool for designing, shaping, maintaining and changing urban functions [6] to be more efficient. Therefore, if we are going to talk about spatial configuration, then, we need to invent ways to talk about it. Since different methods and modeling techniques are invented to study and analyze urban configuration focused on human behaviors in urban space (which is the skeleton of urban configuration) including simple geometrical attributes, such as lines of sight and movement or visual fields of perception creating a network of spatial elements. This network then turns into a pattern of relationships, or a graph representation [7], which can be quantitatively analyzed to determine the relative role that each space plays in the configuration of the system, as a whole or in its parts [6].

\section{SPACE SYNTAX METHOD}

One of the most important techniques and theories of studying spatial configuration is the space syntax method that is a set of theories and methods for modeling and analyzing cities, using space as the fundamental generator of the city. Founded in the 1970s and 1980s by Bill Hillier and his colleagues, and developed further in the following decades, the space syntax theory describes the logic of society through its manifestation in spatial systems $[1,8]$ : How the way spaces are put together -or the configuration of space- relates directly with how people perceive, move through and use spatial systems of any kind, ranging from small scale domestic spaces to large-scale cities [6]. The space syntax research aims to develop strategies of description for configured, inhabited spaces (of buildings, settlements, or built complexes) in such a way that their underlying social logic and can be enunciated [9]. This method denies the assumption of the society as an independent entity and the city the other and puts its central 
hypothesis based on this assumption that the social structure of the city is inherently spatial, and spatial configuration has a social logic fundamentally. As Hillier and Hanson [1] argue that space syntax theory denies the presumption of the spaceas-form and society-as-content distinction.

Before introducing the space syntax method, it is important to note that space syntax is invented based on the mutual relationship between the configuration of space and people activities [1], meaning how one captures and interacts with space. To understand how the relationship between people and space happens, we must understand how, in principle, a configuration of space can be influenced by, or influence, a configuration of people [10].

\subsection{Definition of configuration}

As Hillier [10] argues configuration seems to be a concept addressed to the whole of a complex rather than to its parts. Intuitively, it seems to mean a set of relationships among things all of which interdependent in an overall structure of some kind. If we define spatial relations as existing when there is any type of link -say adjacency or permeability- between two spaces, then configuration exists when relations between two spaces are changed according to how we relate one or other, or both, to at least one other space. In order to understand the concept of the configuration, one of the fundamental patterns illustrated by Hillier [10] is presented in Figure 1.

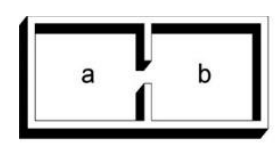

a.

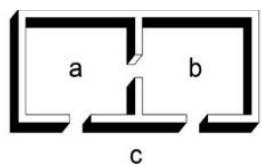

b.

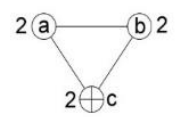

Figure 1. Spatial configuration and j-graph

Simply speaking, Figure 1 is a cell divided into a and b subcell by a partition in which both sub-cell are permeable into each other through an opening in the middle partition. A relationship is formally 'symmetrical' in the sense that cell $a$ is to cell $b$ as $b$ is to $a$. Now consider Figures $1 \mathrm{~b}$ and $1 \mathrm{c}$ in which an external relation namely $c$ in added, in the cell $1 \mathrm{~b}$ both $a$ and $b$ are directly permeable to see, while, in 1c, only $a$ is directly permeable to $c$. This means that in $1 \mathrm{c}$ we must pass through $a$ to get to $b$ from $c$, whereas in $1 \mathrm{~b}$ we can go either way.

We must pass through $a$ to get to $b$ from $c$, but we do not need to pass through $b$ to get to $a$ from $c$. In other words, the relation between $a$ and $b$ has been redefined by the relationship each has to third space, this is a configurational difference. The configuration is a set of interdependent relations in which each is determined by its relation to all the others insofar it is affected by the simultaneous co-presence of at least a third element, and possibly all other elements, in a complex [10].

Such configurational differences can be shown by a graph known as j-graph, presenting how the permeability of spaces is configured with regards to the accessibility. As in $1 b$, the graph is symmetrical based on the permeability pattern of the cell, while in $1 \mathrm{c}$ the graph is linear from $c$ to $a$ sub-cell and then $b$.

Given the above discussion, the aim of the spaces syntax method is studying spatial configuration in how patterns of human co-presence emerge in the network [5] which can assign the sociability potential of urban spaces. Hence, Yoav and his colleague [11] explain that this methodology is based on topological-visual analysis of a built environment that in an attempt aims to explain the movement patterns of both vehicles and pedestrians in urban space $[12,13]$ affecting the floating urban flows, not only movements like pedestrian and traffic but also land-use distribution [12, 14].

\subsection{Theory of natural movement}

The movement generated by the spatial grid creates the life of the city, rejecting the commonly-thought idea of place as one thing and movement between places as another [12]. As a general definition, the relationship between the structure of the urban grid and movement densities along the lines can be called the principle of 'natural movement'. Natural movement is the proportion of movement on each line that is determined by the structure of the urban grid itself rather than by the presence of specific attractors or magnets [10]. Natural movement is the mechanism of generating contact meaning that some locations in the urban grid have more potential to develop the sociability potential of urban space and can lead to socio-economic development and empowering the socioeconomic efficiency of some urban parts. Natural movement is directly affected by the integration value and connectivity of some parts of the urban fabric to the adjacent urban fabric. Natural movement analysis is performed by an axial map, which shows the degree of visual accessibility from the perspective of a person moving in urban space [11].

The axial map is made based on a representation of the street system by a network of straight lines called axial lines [1] and is created by the minimal set of axial lines that fully cover the open spaces in a street network [15]. The axial map is the minimal set of axial lines such that the set taken together fully surveils the system, and that every axial line that may connect two otherwise unconnected lines is included. The axial map is made up of the fewest and longest lines which pass through all the spaces of the system and make all connections [15], although they seem initially to be something of a reduction they have been shown by research to be important to both how people understand spatial patterns and how they use them [16].

\subsection{Depthmap software}

To analyze axial maps in the urban grid, since the beginning of the $20^{\text {th }}$ century, various computational tools and methods have been invented based on examining human movement and visibility in-built context. The most popular of which is UCL Depthmap, a spatial network analysis software created by Alasdair at the UCL University. Depthmap was initially intended for visibility graph analysis [17], but over the years, it has been supplemented with additional routines for axial lines in convex spaces and agent-based analysis [18]. Necessarily, some indicators should be defined to know how to interpret the results of the depthmap analysis, including connectivity, integration (HH, n, R3) and depth. Connectivity measures the number of immediate neighbors that are local measures and reflects the number of axial lines directly intersecting each line in a network [11] and has a direct relationship with integration. Integration as the other indicator 
reflects the average topological distance (number of direction changes) from each line to all the other lines in a network [11] and it is a static global measure, describing the average depth of space to all other spaces in the system.

Analysis and computation of integration in depthmap are based on the value of integration on a global scale (n) or different radii $(\mathrm{R} 3,7)$, and the results of such analysis depict a various range of colors from warm to cold color (Red to Blue). Global integration shows how each street is connected to all others in a city in terms of the maximum possible direction changes, while local integration with radius 3 or 7 shows how each street is connected to its vicinity in terms of three or seven times direction changes. Given the representation of color in integration analysis, the warm color lines (red lines) show the streets with the highest integration values, while the cold ones (blue ones) show the most segregated ones. Higher integration values of nodes, therefore, indicates that the node is less deep on an average from all other nodes, or in other words, that it is more integrated into the spatial system [9] and finally the more integrated space, the more social effect to generate higher rates of movement and co-presence [17]. Accordingly, the integration has a direct relationship with the sociability potential of urban space because the value of integration explains to what extent an urban axis or urban space has sociospatial coherence with its adjacent context and basically, can explain the sociability nature of urban fabric based on its connectivity, depth, visibility, and readability of urban contexts.

\section{RESEARCH METHODOLOGY}

The research methodology of this paper is a mixed-method consisting of library research, space syntax method (softwarebased) and the questionnaire technique (field study). The driving force behind assigning this methodology is the necessity of the validation of depthmap software results (in terms of the integration analysis and its effects) through the technique of the questionnaire. To achieve this aim, in the library research, the background of the topic and the relevant research with the same technique are studied. In the second part of the research, through the space syntax method, the value of urban integration in the urban configuration of Kermanshah city and Golha Street in both global and local scales by depthmap software is analyzed and the results are shown. The analysis depicts different values of integration from the most to the least integrated urban spaces in Kermanshah and specifically in Golha Street as one of the most integrated urban spaces in the city. In the third step, to validate the results of the depthmap analysis, a questionnaire technique is devised according to seven indicators, including social interactions, sense of vitality, personal and social identity, collective memory, sense of community, sense of invitation, and safety. The questionnaires are distributed among 120 citizens randomly ranging from various genders and age groups (18-75) within May 2019. The answer sheet has a quantitative content (a numerical format) with five numbers from 1-5 and any interviewees can answer differently and simply based on his point of view about any indicator. The gathered answer sheets are analyzed by SPSS, and the results of the SPSS illustrated with different tables such as the descriptive statistics table to show the max and mean measures, and also the Pearson correlation and significant measures extracted from SPSS.

\section{RESEARCH BACKGROUND}

As a space syntax method based research accomplished by Abbaszadehgan and his colleagues [19], the relationship between the spatial structure and development value of the neighborhood in Mashhad city is analyzed. Hence, 136 neighborhoods in Mashhad city are analyzed by depthmap software, and the results show there is a strong and meaningful relationship between the indicators of urban development and higher local integration, while in the value of global integration the results are the opposite. Consequently, the author summarizes that increasing the socio-economic inequalities in Mashhad, especially between Western and Eastern parts, is the result of such an unbalanced development. Similarly, less integrated neighborhood networks in urban fabric, more spatial segregation and less accessibility into surrounding contexts.

In other research accomplished by Izadi and Sharifi [20], they investigate the value of coherence and integration in the city of Hamadan in three different periods 1918, 1954 and 2014 by depthmap and the results show by the passage of time from 1918 to 2014 the value of urban integration has decreased gradually. The findings illustrate that the development of the city has led to decreasing urban integration and decreasing the inner city areas' coherence in Hamedan.

Similarly, as historic research done by Abedini and colleagues [21], the role of urban development plans on the spatial configuration of the historic part of Orumieh city in four different years in 1933, 1976, 1994, and 2016 by space syntax method is put under analysis. So through this research, all urban maps in four years went into analysis by depthmap to be analyzed the developing parts towards the historic part of the city. The result depicts that the development of the city had led to a decrease in the integration value of the historic part towards the developing urban parts and such changes have had negative effects on internal coherence and integration of the urban configuration.

Given the content of this research, the authors of this paper could not find any research regarding the role of space syntax on urban analysis of Kermanshah to study the social phenomenon, and it seems this is a new window to begin such research.

\section{CASE STUDY (GOLHA STREET)}

Kermanshah city is the center of Kermanshah province, located $500(\mathrm{~km})$ from Tehran in the west of Iran and according to the 2015 census, its population is $1,083,833$ [22]. Golha Street is located in the northern part of Kermanshah which acts as a central axis in the Maskan neighborhood to connect all parts of the neighborhood (Figure 2).

Golha Street embodies a high-density urban texture, including residential and commercial spaces, public services and act as a dynamic walkable environment, and during the recent decade, due to the centrality of the street in Maskan neighborhood socially and economically, the private sectors have invested dramatically in this street as the beneficiary of such fast development. The length and width of Golha Street are 2300 and 22 meters respectively covering the Moallem Square and the company of Ready Mix Concrete Supplier. The street surrounded by commercial and residential buildings along the street.

Concerning the spatial analysis accomplished by depthmap 
software and field observations, Golha Street is one of the most integrated urban spaces in Kermanshah which has a high value of accessibility, connectivity, and readability to the adjacent neighborhood (Maskan) in municipality district 5 (28410 people), similarly Maskan neighborhood is located in municipality district 5 , the most populated district among eight municipalities (173,838 people) [22]
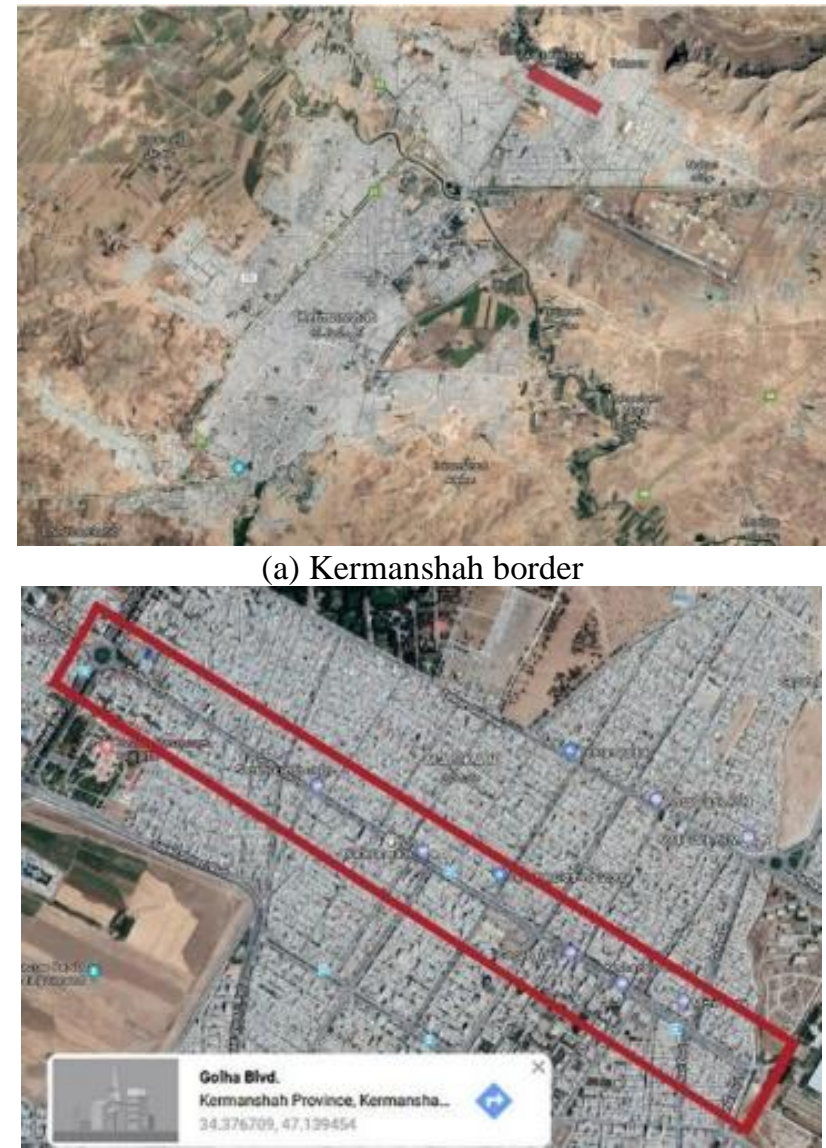

(a) Golha street

Figure 2. Golha Street, Kermanshah, Iran. Source: Google map. Figure - Depth Map

\section{INTEGRATION ANALYSIS OF KERMANSHAH AND GOLHA STREET (MASKAN)}

Analysis of global integration (HH) in Kermanshah city by depthmap (the left map in Figure 3), shows there are two most integrated urban zones in municipality district 2-3 and 5 in turn based on the integrated core shown by yellow and green color. Quantitatively the value of integration in depthmap software is calculated by the numeric values, meaning the higher in the integrated urban configuration.

Considering such quantitive basis the findings of the research depict the global integration value in Kermanshah embodies a vast range of quantities from -1 to 0.589 and Golha Street, located in the core integrated part of district 5 has the highest value of integration up to 0.592 compared with all urban spaces in the city.

Besides, the integration analysis R3 in Kermanshah (the right map in Figure 3) embodies a range of integration in different districts from -1 to 4.225 based on the spatial configuration of the city. Similarly, the mentioned districts (2, 3 and 5) have the greatest value of integration R3 and Golha Street located at the district 5 in Maskan neighborhood located at the center of the integrated core (4.19 value).

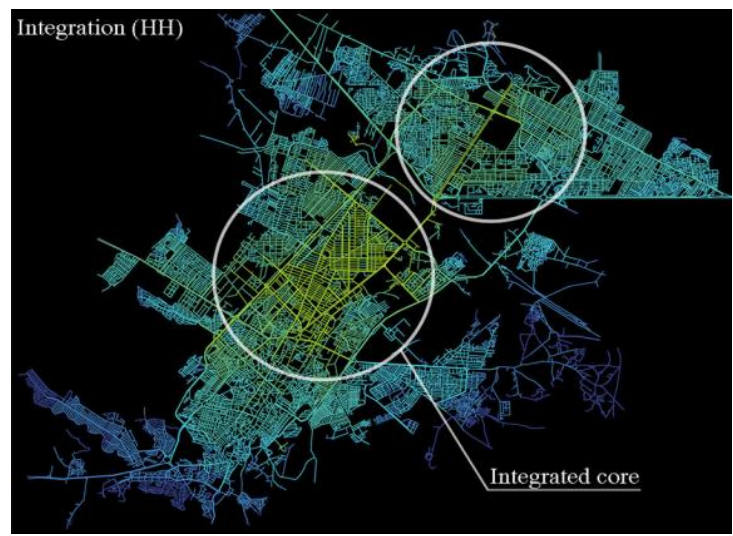

Global integration (n)

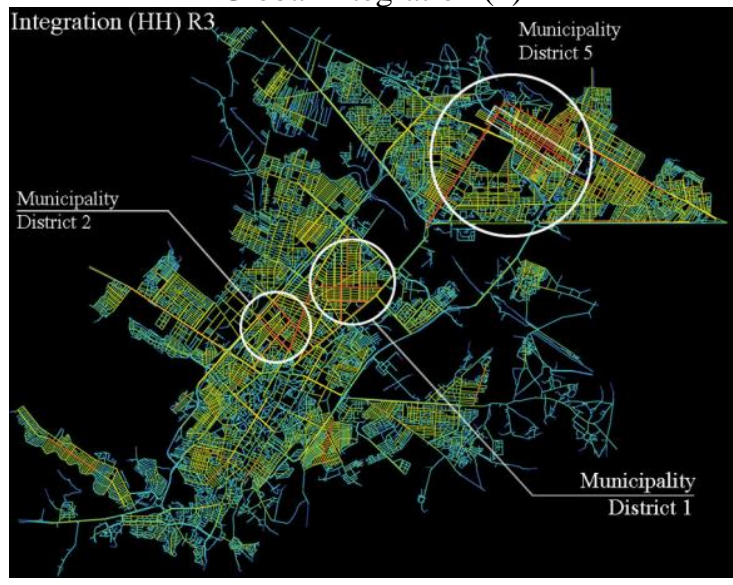

local integration R3

Figure 3. Integration analysis

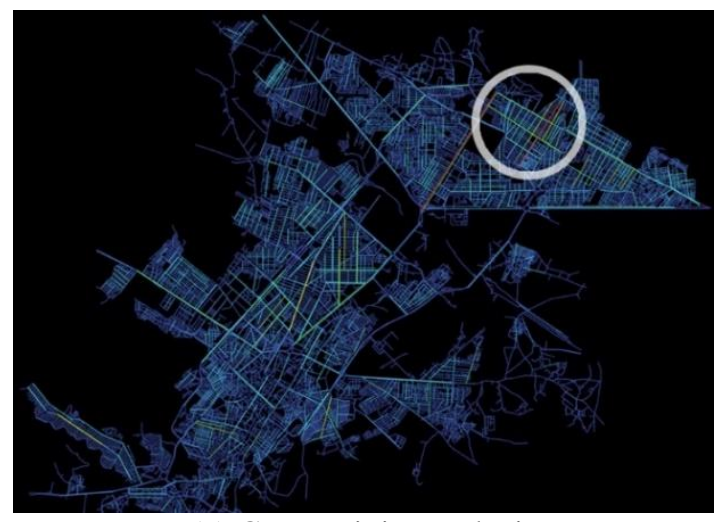

(a) Connectivity analysis

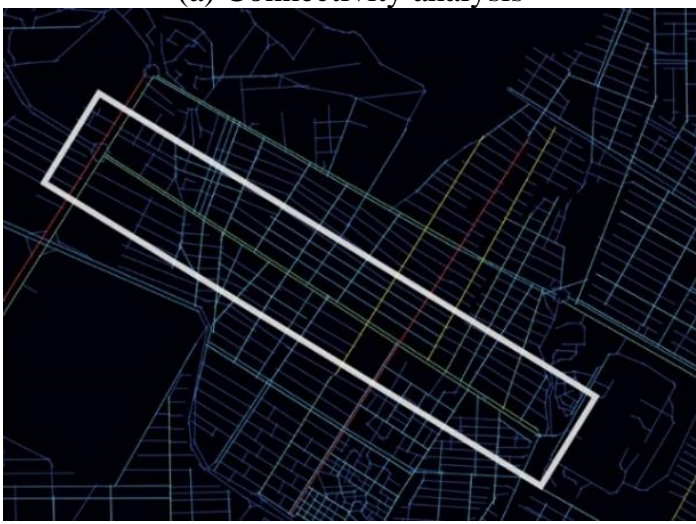

(b) Connectivity analysis

Figure 4. Connectivity analysis in Kermanshah city and Golha Street. Source: Depthmap analysis 
The other important indicator (connectivity) proves that Golha Street has a high value of connectivity up to 25 compared with the average of connectivity in Kermanshah city embodying a range between 0-35 (Figure 4). Accordingly, the results of integration analysis show that in the urban configuration of Kermanshah two northern and central parts of the city have the highest value of integration (in global scale) due to the configuration of the city as divided into two parts by Qarasu river, passing from the northwest to southeast and makes an urban division between the north and south part of the city.

\section{QUESTIONNAIRE TECHNIQUE (VALIDATION OF INTEGRATION ANALYSIS)}

To validate the results of integration and connectivity analysis (depthmap analysis) in Golha Street, a questionnaire technique is used. One of the most common quantitative research tools in survey research is the questionnaire technique used in the process of data collection and consisting of a set of targeted questions to measure people's perspectives about a subject.

Likewise, using a questionnaire is due to the complexity and the impossibility of studying the extensive statistical population. Hence, the researcher examines the research variables by selecting a sample group that represents the statistical population.

Although sociability potential of urban spaces comprises a wide range of socio-economic and cultural parameters, given the basis of this research which is the validation of urban integration analysis, a questionnaire is devised with seven social indicators, including social interactions, creating and enhancing the sense of vitality, making personal and public identity, creating collective memory, creating a sense of community, promoting the sense of invitation and safety. This questionnaire was distributed among 120 interviewees ranging from both male and female, different age groups (18-75 years old) and various users in Golha Street in May 2019 for one month. To facilitate the evaluation of indicators by people, the answer sheet has a numerical format consisting of five numbers (1-5), meaning the higher quantity the higher effect of Golha Street on enhancing an indicator and vice versa. The gathered data are analyzed by SPSS software and the results are explained in the following, but before explaining the outcomes of the SPSS, the indicators of the questionnaire are elucidated extracted from the article written by Peyman et al [23]. These indicators are the agglomeration of all social characteristics of urban spaces.

\subsection{The following indicators are chosen based on research goals that consider the social aspect of public spaces}

\subsubsection{Social interactions}

The main function of public spaces is the development of social interactions among citizens as Jane and William believe such interactions are vital for the life of a city as well as the life of society in general [24].

\subsubsection{Creating and enhancing the sense of vitality}

Vitality is one of the most important indicators of successful public space leading to an improvement in the quality of social life, as Jan and Lars [25] and Vikas [26] provide further evidence that the quality of public space is linked to social use and liveliness. Furthermore, Kevin [27] identifies the vitality as one of the performance dimensions of urban design and describes it as the degree to which the form of places supports the functions, biological requirements, and capabilities of human beings.

\subsubsection{Making personal and public identity}

Identity is not an innate quality of man, and it is made by sharing experiences and activities within society [27]. Intrinsically, public spaces are not able to produce identity, but as a container provides the possibility of realization of personal and public identity.

\subsubsection{Creating collective memory}

Collective memory is shaped while spending time with others and engaging with their activities passively or actively, and public space has the potential to facilitate happening these activities.

\subsubsection{Creating a sense of community}

Sense of community means a sense of belonging and experiencing the community, made by mixing with others, as Anthony and Zachary [24] explain the close social bonds we develop in public spaces provide a sense of belonging and security. The interest in the broader built environment and its influence on the sense of community is gaining momentum nowadays, as studies prove that perceived the quality of public open spaces and the shopping amenities have a positive and significant association with a sense of community [28].

\subsubsection{Promoting the sense of invitation}

Making an inviting environment can act as a gathering place to attract the public as William's study of the public squares [29] in New York in the 1970s and 1980s reveals people like to go where others are. These social realms embody various social groups, regardless of age, religion, gender, ethnicity and make a public and inclusive territory for all. As an inclusive feature, public spaces act as a melting point for all social groups, including the marginal, the forgotten, the silent, Akhtar [30], and undesirable social minority groups like informal vendors, street people with different abilities like women, children, elderly, and others marginalized in the community [26].

\subsubsection{Safety}

The bedrock attribute of a successful city district is that a person must feel personally safe and secure on the street among all strangers [31]. According to research, making safety in public space embodies a vast range of environmental features and social surveillance from a good city layout [32] to a sensory attribute amongst the attractiveness of public spaces $[33,34]$ and as social surveillance.

\subsection{Data descriptive survey}

The data gathered through the questionnaire are analyzed by SPSS and in the first part. Table 1 depicts the results and from left to right, the columns are the indicators column, the number of correct answer sheets, maximum and minimum quantities, mean of max and min and finally the last column the standard deviation respectively. The standard deviation measures the dispersion of a data set relative to its mean and is calculated as the square root of the variance. It is calculated as the square root of variance by determining the variation between each 
data point relative to the mean. If the data points are further from the mean, there is a higher deviation within the data set; thus, the more spread out the data, the higher the standard deviation [35], also, the fewer differences between the Max and Min quantities the less standard deviation and vice versa. As an explanation, in this table, the relationship between maximum and minimum quantities shows a different value of effectiveness of Golha Street on the social indicators based on interviewees' viewpoints. Although the maximum quantities are close to each other, the minimum quantities are different, for instance. In the mean column, there are various measures from the highest value, such as social interaction (4.43/5) and a sense of invitation (4.00/5) to the lowest quantities, including personal and public identity (3.16/5) and sense of community (2.57/5). The effectiveness value of Golha Street on social indicators can be evaluated based on standard deviation. It means the more tendency towards 0 the more effective the value of Golha Street on a specific indicator and vice versa. Accordingly, Golha Street has the highest social effect on the sense of invitation with 0.225 and safety and social interaction with 0.423 and 0.497 in the next steps, while it has the lowest effect on personal and public identity with 1.262. Mean explains the average of max and min of every indicator in every indicator, while Sd. explains the number of fluctuations between the highest and the lowest indicators.

8.2.1 Evaluation of the effectiveness value of Golha Street on indicators

One-Sample Test is used to describe the results of the descriptive information. In Table 2, mean 3.01 confirms that the mean of Golha Street's effectiveness on the indicators used in the research. Furthermore, the results illustrated in Table 2 shows that the significance value of indicators is 0 , indicating the differences between the indicators statistically are meaningful, and conceptually it means that the indicators are assigned based on a semantic cohesion, and the Sd shows an acceptable trend toward 0.00 to 0.2605 .

\subsubsection{Pearson correlation coefficient}

The Pearson correlation coefficient is a measure of the strength of a linear association between two variables and is denoted by $r$. A Pearson correlation attempts to draw a line of best fit through the data of two variables, and the Pearson correlation coefficient $r$ indicates how far away all these data points are in this line of best fit. The Pearson correlation coefficient, $r$, can take a range of values from +1 to -1 . A value of 0 indicates that there is no association between the two variables, and greater than 0 indicates a positive association; that is, as the value of one variable increases, so does the value of the other variable. A value less than 0 indicates a negative association; that is, as the value of one variable increases, the value of the other variable decreases [36]. Table 3 presents the results obtained from Pearson correlation analysis, the correlation coefficient and the relevant $\mathrm{p}$-value. $\mathrm{R}$ is obtained 0.650 with a significance of 0.000 . Based on the results, the quantity explains the significant correlation between the impact of Golha Street and social indicators of the questionnaire.

Table 1. Descriptive statistics

\begin{tabular}{cccccc}
\hline Indicators & N & Min & Max & Mean & Standard Deviation \\
\hline Social interactions & 119 & 4 & 5 & 4.43 & 0.497 \\
Sense of vitality & 119 & 2 & 5 & 3.76 & 0.909 \\
Personal and public identity & 119 & 1 & 5 & 3.16 & 1.262 \\
Collective memory & 119 & 2 & 5 & 3.29 & 1.174 \\
Sense of community & 119 & 1 & 4 & 2.57 & 0.962 \\
Sense of invitation & 119 & 3 & 5 & 4.00 & 0.225 \\
Safety & 119 & 2 & 5 & 3.92 & 0.423 \\
Mean & N & Mean & Std. Deviation & Std. Error & Mean \\
& 119 & 3.01 & 0.2605 & & 0.0238 \\
\hline
\end{tabular}

Table 2. Significance value- one-sample statistics

\begin{tabular}{cccccc}
\hline & Test Value $=\mathbf{0}$ & & & & \\
\hline Indicators & Statistics & Degree of Freedom & Significance Value & Mean Difference & $95 \%$ Confidence Interval of the Difference \\
Statistics & 126 & 118 & 0.000 & 3.01 & 2.96 \\
\hline
\end{tabular}

Table 3. The extent of the correlation coefficient with the sustainability indicator

\begin{tabular}{cccc}
\hline & \multicolumn{3}{c}{ Correlation } \\
\hline \multirow{4}{*}{ Golha Street } & Golha Street & Indicators \\
& Pearson Correlation & 1 & 0.650 \\
& Significance & & 0.000 \\
& Number & 119 & 119 \\
\hline
\end{tabular}

\section{DISCUSSION AND CONCLUSION}

Comparatively, studying the relationship between integration and sociability potential of urban spaces is a very complicated analysis. As a method and a technique to analyze such a relationship, inventors of space syntax believe this technique and its relevant tools like depthmap can analyze the spatial configuration of urban space which analyzes the relationship between space and social phenomena like natural movement of pedestrians and traffic patterns. This means that depthmap as a software to do such an analysis can assign the socio-spatial patterns of urban configuration (more integrated urban space, the more sociability potential of urban space).

But as a contradict, normally, the value of urban integration 
does not have a direct relationship with the social patterns of urban spaces based on research. Take the integration analysis (R3) in Kermanshah as an example, in which, there are some contradicts between integration analysis results and the sociability potential of urban spaces according to the field observations. Analysis of Kermanshah city (R3) shows there is relatively a high value of local integration (n) in Chaman neighborhood (3.54), located in the west of Kermanshah in municipality district 8 while after a field study it is proven that this neighborhood is segregated socially and economically in terms of safety, social interactions and economic indicators. Chaman is a segregated and undeveloped community despite its proximity to the urban context, while the local integration analysis shows the main street of this neighborhood is an integrated urban axis connecting all parts of the neighborhood.

Therefore according to the findings of this research, to reconcile the value of integration in urban spaces and sociability potential of urban spaces, we must assign the overlapped integrated urban areas in both local and global integration analysis and then the intersection of both analysis can be compared with the social indicators of urban spaces through questionnaire technique. Accordingly, first, we must specify the global integration in a city and similarly on the local scale, then the common results of both integration analysis can be compared with the value of the sociability potential analysis. For instance, Golha Street, as the case study of the research, located in the integration core [37], (in globaln) of Kermanshah city and simultaneously, in the local integration analysis, this street has the highest value of integration as an urban axis in Maskan neighborhood. The high integration value of Golha Street in both global and local scales has the same effect on enhancing the social indicators of space which improve the sociability potential of urban spaces based on field study (questionnaire technique). In sum, to investigate the more sociable urban areas, first analyzing the integration of both global and local values is necessary to find the integrated overlaps, subsequently, defining the more social urban spaces is possible.

This research aims to study the relationship between the value of integration in urban configuration and the sociability potential of Golha Street as one of the densest urban areas in the city of Kermanshah, Iran. The research methodology is a mixed-method including library research, software analysis (depthmap) and the questionnaire technique to validate the results of the depthmap analysis. According to the findings of the first part of the research in the global scale, the municipality district 2, 3 and 5 respectively have the highest value of urban integration compared with 5 other districts, and in the local scale, integration analysis (R3) of the urban configuration of the city depicts that Golha Street located in district 5 has a high mean integration up to 4.19 , which can be considered as the most integrated parts in the City. In the second part of this research, to validate the results of depthmap a field study through a questionnaire technique is used. This questionnaire has seven indicators and was distributed among 120 interviewees ranging from different genders and age groups within May 2019. In the analysis part, as the questionnaire has a quantitative answer sheet (a numerical answer sheet from 1-5), the mean of answers depicts the social interaction received the highest measure by $4.43 / 5$, meaning the Golha Street has the highest effect on social interaction based on public point of view. This indicator is followed by the indicator of the sense of invitation by 4.0 and closely by safety with 3.92. Similarly, other indicators stand in lower values such as the sense of vitality, collective memory and personal and public identity with $3.76,3.29$ and 3.16 respectively, and sense of community received the lowest attention with 2.57 , generally, the total mean shows an acceptable measure of all measures with 3.01, meaning Golha Street has a noticeable effect on empowering the sociability potential of the neighborhood. Similarly, based on descriptive statistics the standard deviation oscillates between 0.225 (sense of invitation) and 1.17 (collective memory) in turn and a mean of 0.2605 , proving that the deviation of indicators is limited and there is a strong semantic meaning between them. The Pearson correlation in this analysis is 0.650 showing a correlated relationship between indicators and sociability potential in Golha Street.

Generally, Golha Street has been successful to act as an integrated core in the Maskan neighborhood to develop the indicators of the sociability potential of urban space. The results prove that there is a direct relationship between the value of integration and the sociability potential of urban spaces in Kermanshah city.

\section{ACKNOWLEDGMENT}

The authors would like to thank you many students who cooperate in the process of doing questionnaires in Kermanshah city, especially those helping at Sama Technical and Vocational Training College, Islamic Azad University, Kermanshah Branch, Kermanshah Iran.

\section{REFERENCES}

[1] Hillier, B., Hanson, J. (1989). The Social Logic of Space. Cambridge University Press. http://dx.doi.org/10.1017/CBO9780511597237

[2] Lefebvre, H., Kofman, E., Lebas, E. (1996). Writings on Cities (Vol. 63). Oxford: Blackwell.

[3] Westin, S. (2010). Space syntax and geography: a question of logic and dialectics. The Journal of Space Syntax: Architecture, Urbanism, Society, 1(1): 254-257.

[4] Hillier, B. (2005). Between social physics and phenomenology: Explorations towards an urban synthesis? Nes, A. van (ed.) 5th International Space Syntax Symposium Proceedings, Delft, Netherlands.

[5] Hillier, B. (2008). Space and spatiality: What the built environment needs from social theory. Building Research \& Information, 36(3): 216-230. http://dx.doi.org/10.1080/09613210801928073

[6] Karimi, K. (2018). Space syntax: consolidation and transformation of an urban research field. Journal of Urban Design, $23(1)$ : 1-4. http://dx.doi.org/10.1080/13574809.2018.1403177

[7] Freeman, L.C. (1977). A set of measures of centrality based on betweenness. Sociometry, 40(1): 35-41. http://dx.doi.org/10.2307/3033543

[8] Hillier, B., Burdett, R., Peponis, J., Penn, A. (1986). Creating life: Or does architecture determine anything? Architecture \& Comportement/Architecture \& Behaviour, 3(3): 233-250.

[9] Bafna, S. (2003). Space syntax: A brief introduction to its logic and analytical techniques. Environment and Behavior, 35(1): http://dx.doi.org/10.1177/0013916502238863 
[10] Hillier, B. (2007). Space is the Machine: A Configurational Theory of Architecture. Space Syntax, London, UK.

[11] Lerman, Y., Rofè, Y., Omer, I. (2014). Using space syntax to model pedestrian movement in urban transportation planning. Geographical Analysis, 46(4): 392-410. http://dx.doi.org/10.1111/gean.12063

[12] Hillier, B., Penn, A., Hanson, J., Grajewski, T., Xu, J. (1993). Natural movement: Or, configuration and attraction in urban pedestrian movement. Environment and Planning B: Planning and Design, 20(1): 29-66. http://doi.org/10.1068/b200029

[13] Turner, A. (2007). From axial to road-center lines: a new representation for space syntax and a new model of route choice for transport network analysis. Environment and Planning B: Planning and Design, 34(3): 539-555. https://doi.org/10.1068/b32067

[14] Hillier, B., Iida, S. (2005). Network and psychological effects in urban movement. In International Conference on Spatial Information Theory, Springer, Berlin, Heidelberg, pp.

475-490. http://dx.doi.org/10.1007/11556114_30

[15] Turner, A., Penn, A., Hillier, B. (2005). An algorithmic definition of the axial map. Environment and Planning B: Planning and Design, 32(3): 425-444. http://dx.doi.org/10.1068/b31097

[16] Hillier, B. (1985). The nature of the artificial: the contingent and the necessary in spatial form in architecture. Geoforum, 16(2): 163-178. http://dx.doi.org/10.1016/0016-7185(85)90026-0

[17] Turner, A. (2001). Depthmap: A program to perform visibility graph analysis. In Proceedings of the 3rd International Symposium on Space Syntax, pp. 31-12.

[18] Paliou, E., Lieberwirth, U., Polla, S. (eds.) (2014). Spatial Analysis and Social Spaces: Interdisciplinary Approaches to the Interpretation of Prehistoric and Historic Built Environments (Vol. 18). Walter de Gruyter. http://dx.doi.org/10.1515/9783110266436

[19] Abbaszadegan, M., Mokhtarzadeh, S., Bidram, R. (2012). A study of the relation between the spatial structure of the city and the quality of urban development using Space Syntax A case study of Mashhad.

[20] Izadi, M., Sharifi, A. (2016). Evaluating carl frish's design on spatial structure configuration concerning old contexture in hamadan (using space syntax technique).

[21] Abedini, A. Sobatsani, N., Golshani, M. (2019). Assessment of the impacts of physical changes on the urban spatial structure in Urmia historical district by space syntax and GIS. Human Geography Research Quarterly, 51(1): 79-96.

[22] Kermanshahan Statistics. (2018). Kermanshah Planning and Budget Organization Press.

[23] Amiriparyan, P., Reicher, C., Kiani, Z. (2019). Analyzing the effectiveness value of public spaces on sociability potential of cities case study: Nobahar street, Kermanshah, Iran. WIT Transactions on Ecology and the Environment, 238:

119-130. http://dx.doi.org/10.2495/SC190111
[24] Orum, A.M., Neal, Z.P. (2009). Common Ground? Readings and Reflections on Public Space. Routledge, New York. http://dx.doi.org/10.4324/9780203873960

[25] Gehl, J., Gemzøe, L. (2004). Public Spaces-Public Life. The Danish Architectural Press.

[26] Mehta, V. (2013). The Street: A Quintessential Social Public Space. Routledge, London. http://dx.doi.org/10.4324/9780203067635

[27] Lynch, K. (1960). The Image of the City. The M.I.T. Press.

[28] Francis, J., Giles-Corti, B., Wood, L., Knuiman, M. (2012). Creating sense of community: The role of public space. Journal of Environmental Psychology, 32(4): 4019. http://dx.doi.org/10.1016/j.jenvp.2012.07.002

[29] Whyte, W.H. (1980). The Social Life of Small Urban Spaces. Project for Public Spaces Inc.

[30] Badshah, A.A. (1996). Our Urban Future: New Paradigms for Equity and Sustainability. London and New Jersey.

[31] Jacobs, J. (1992). The Death and Life of Great American Cities. Vintage, New York. http://dx.doi.org/10.1002/9781119084679.ch4

[32] Gehl, J. (2013). Cities for People. Island Press, Washington, D.C.

[33] Childs, M.C. (2006). Squares: A Public Place Design Guide for Urbanists. UNM Press, New Mexico.

[34] Marcus, C.C., Francis, C. (1997). People Places: Design Guidelines for Urban Open Space. Second Review end edition. John Wiley \& Sons.

[35] Chen, J. (2020). Investopedia. http://www.investopedia.com/terms/d/doublebottom.asp

[36] Laerd Statistics. https://statistics.laerd.com, accessed on Jun. 2019.

[37] Turner, A. (2004), DepthMap4: A Researcher's Handbook, UCL, pp. 29

\section{APPENDIX}

(1) A justified map/graph is one in which a node is drawn at the base, and all points of depth 1 from that point are aligned horizontally immediately above it, all points at depth 2 from that point above those at depth 1, and so on until all levels of depth from that point are accounted for [1].

(2) Convex space is one in which no straight line drawn between any two points goes outside the space [1]

(3) Node count, also called $\mathrm{k}$ in Confeego, measures the number of lines (or segments) encountered on the route from the selected line (or segment) to all others [3].

(4) Integration core is a pattern made of the $10 \%, 25 \%$ or $50 \%$ most integrating spaces, or of a given number of spaces if the system is large and complex [1]

(5) As an ongoing doctoral thesis, this part of the research is focused on studying the sociability potential of three streets including Nobahar Street, Golha Street, and Kashani Street simultaneously in Kermanshah. Hence, it must be explained that the results are the same compared with the last article written by the author [22]. 